\title{
Neoumbilical Reconstruction as an Adjuvant Procedure in Abdominoplasty
}

\author{
Emad K. Bayumi \\ Crimean Medical Academy named after S.I. Georgievsky Crimean Federal University named after V.I. Vernadsk, Crimea, Russia
}

\author{
Email address: \\ Emadsurg666@hotmail.com
}

\section{To cite this article:}

Emad K. Bayumi. Neoumbilical Reconstruction as an Adjuvant Procedure in Abdominoplasty. Journal of Surgery. Special Issue: Abdominal Surgery: Toward the Best. Vol. 4, No. 1-1, 2016, pp. 16-18. doi: 10.11648/j.js.s.2016040101.14

\begin{abstract}
Introduction: Neo-umbilicus construction is usually needed post abdominoplasty and in some techniques the umbilicus needs resection after repeated abdominoplasty. There are many techniques for umbilical reconstruction and the common objective of all these techniques is to create a new umbilicus that looks natural in terms of location, size and depth. The author in this study described a new and simple technique for umbilical reconstruction. Patients and methods: The present study included 50 cases who were subjected to abdominoplasty and neo-umbilicoplasty in Crimean Medical Academy named after S.I. Georgievsky Crimean Federal University named after V.I. Vernadsk Russia in department of general and gastrointestinal surgery. The study started from January 2010 to may 2015. End points: The primary end point of the study was the aesthetic appearance of the new umbilicus and the second end point was patient satisfaction of the operative outcome. Results: Over 50 cases of abdominoplasty we performed reconstruction of the umbilicus with a new and simple technique. There were 40 females and 10 males with age ranging from 28 to 52 years with the mean value as $40 \pm 7.35$ years. Conclusion: The technique for reconstruction of the umbilicus presented in the present study is a simple technique without complications, with long term success and good aesthetic appearance The new constructed umbilicus exhibits appropriate features of both depth and size and avoids the appearance of scarring and secondary stenosis.
\end{abstract}

Keywords: Neoumbilical Reconstruction, Abdominoplasty, New Technique

\section{Introduction}

The umbilicus is an important and essential aesthetic component in the abdomen and it is a centrally placed depressed scar surrounded by skin folds, forming superior hood. The shape of the umbilicus is elliptical in vertical direction or T-shaped with the long axis lying vertically in the mid-line [1]. The aesthetic outcome of the umbilicus is often affected by improper positioning by low placement or shallow, flat appearance in the late postoperative period. Disappointing positioning and shape of the umbilicus, along with periumbilical scarring, are the usual drawbacks of abdominoplasty $[2,3]$.

Neo-umbilicus construction is usually needed post abdominoplasty and in some techniques the umbilicus needs resection after repeated abdominoplasty [4]. There are many techniques for umbilical reconstruction and the common objective of all these techniques is to create a new umbilicus that looks natural in terms of location, size and depth $[1,5,6]$. The author in this study described a new and simple technique for umbilical reconstruction.

\section{Patients and Methods}

\subsection{Patients}

The present study included 50 cases who were subjected to abdominoplasty and neo-umbilicoplasty in Crimean Medical Academy named after S.I. Georgievsky Crimean Federal University named after V.I. Vernadsk Russia in department of general and gastrointestinal surgery. The study started from January 2010 to may 2015 .

Written consents were obtained from all patients before the study. The steps of both operative interferences were explained to all patients. The local ethics committee had approved all operative procedures. Ethical approval for this study department of general and gastrointestinal surgery Crimean Medical Academy named after S.I. Georgievsky Crimean Federal University named after V.I. Vernadsk Russia. 


\subsection{Operative Techniques}

After completion of the abdominoplasty the site of the new umbilicus was chosen to be placed $3 \mathrm{~cm}$ above the line joining both the anterior superior iliac spines $[1,2]$.The selected position was marked and being pushed by the assistant using his index finger covered by protecting plastic cap [Figure1]. Defatting was performing guided by the pushing action of my assistant's index finger ensuring formation of button-like clear area opposite the proposed site of the new umbilicus.

With the use of proline $2 / 0$, five stitches were constructed in the selected site through the subdermal plane with care of not transfix skin and with no fear of assistant index puncture (protected by plastic cap) designed as four corners stitches from the subdermal level to the anterior rectus sheath covered by the mesh after finishing abdominoplasty and $5^{\text {th }}$ stitch was fixed in the middle of that button shaped area designed for the neoumbilical site. After finishing the five stitches, both upper and lower flaps were sutured together using vicryl $2 / 0$ as subcuticular sutures [Figure2,A and $\mathrm{B}]$.

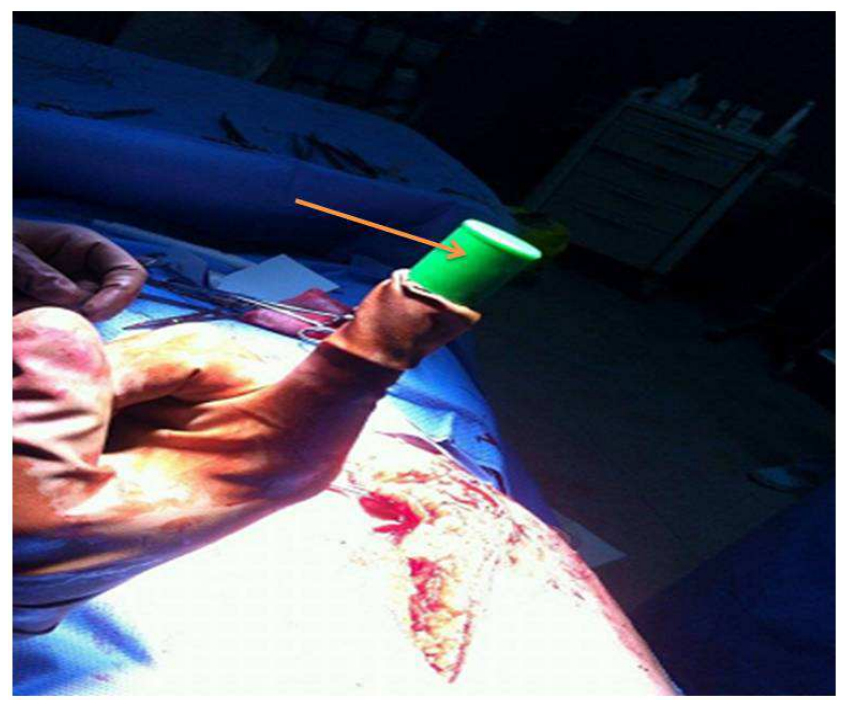

Figure 1. An intraoperative photograph showing the protective cap applied to the index finger of the assistant.

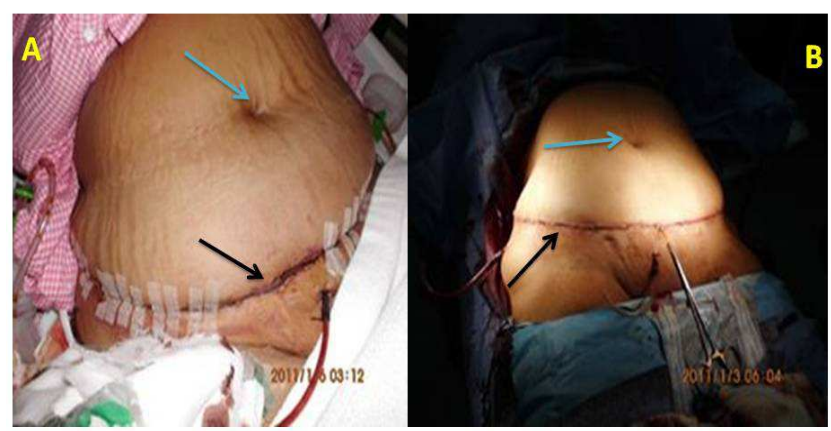

Figure 2. An intraoperative photograph [A and B] showing the sutureless umbilicus in the proper place marked by the blue arrows and the abdominoplasty incisions as denoted by the back arrows.
A

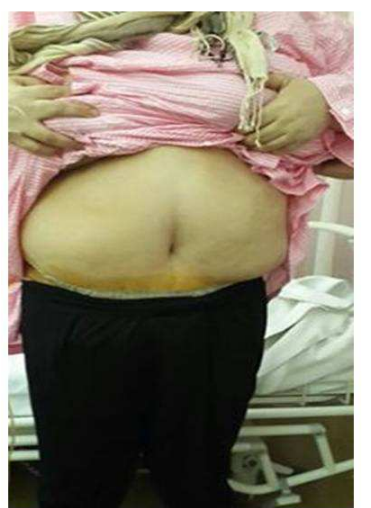

Figutr 3. A postoperative photograph showing the final aesthetic appearance of the umbilicus in relation to the operative scar.

\subsection{End Points}

The primary end point of the study was the aesthetic appearance of the new umbilicus and the second end point was patient satisfaction of the operative outcome.

\section{Results}

Over 50 cases of abdominoplasty we performed reconstruction of the umbilicus with a new and simple technique. There were 40 females and 10 males with age ranging from 28 to 52 years with the mean value as $40 \pm 7.35$ years.

\section{Discussion}

Reconstruction of the umbilicus is a procedure that refines the outcomes of abdominal surgery and its absence significantly affects the aesthetics of the abdomen, making it an essential part of the anatomy. The aesthetic appeal of the abdomen is directly related to good umbilical conformation [7]. The absence or disfigurement of the umbilicus is both cosmetically and psychologically distressing to patients. The goal of aesthetically pleasing umbilical reconstruction is to create a neoumbilicus with sufficient depth and good morphology, with natural-looking superior hooding and minimal scarring [8]. Umbilicoplasty is required not only in conditions such as congenital absence due to bladder exstrophy, gastroschisis, omphalocele, and cloacal exstrophy, but also in cases of a protruding umbilicus, traumatic umbilical malformation, and after abdominoplasty, breast reconstruction using abdominal tissues, umbilical herniorrhaphy, and laparotomy [1,8]. In our study, umbilical reconstruction was performed in abdominoplasty and in deformed umbilicus due to huge Paraumbilical hernias.

There are different techniques for reconstruction of the new umbilicus after abdominoplasty and following large paraumbilical hernial surgery [4]. In some techniques circum-umbilical skin resection and tightened purse- string, the remaining deformed umbilicus is excised [4,9]. 
Neoumbilicoplasty can be performed by lateral skin excisions and a rotation of two small paramedian flaps, by designing two flaps with V-Y advancement or by creating three simple triangular flaps and suturing their apices after defatting the skin flaps to the muscular plane [1]. Despite our technique for neoumbilicus reconstruction in so simple, the techniques described above are either unsatisfactory or too complex $[8,10]$

An elliptical skin island with fat excisions underneath and depression created through a pursestring suture was reported by Marconi [11]. However, this technique requires thorough wound care for an extended period, as it leaves an open wound after the procedure [12] while our new technique required no additional wound dressing or care. A simple technique of using the purse string suture to reconstruct the inner walls of neoumbilicus was reported with satisfying results [ 13]. The purse-string suture as a complementary technique of neoumbilicoplasty keeps the shape of the umbilicus but the long-term effects such as widening, stenosis, or external scars may occur [14]. A new scarless umbilicoplasty technique, which bears many of the characteristics of an ideal needs; it is easy to perform and results in the complete absence of visible scars and with a preferred vertical orientation [15]. In our technique, we performed the neoumbilical construction with no skin excision, no flaps or visible scars.

\section{Conclusion}

The technique for reconstruction of the umbilicus presented in the present study is a simple technique without complications, with long term success and good aesthetic appearance The new constructed umbilicus exhibits appropriate features of both depth and size and avoids the appearance of scarring and secondary stenosis .

\section{References}

[1] Al-shaham AA. Neoumbilicoplasty is a useful adjuvant procedure in Abdominoplasty. Can J Plast Surg. 2009 Winter; 17(4): e20-e23.
[2] Bartsich SA, Schwartz MH. Purse-string method for immediate umbilical reconstruction. Plast Reconstr Surg J. 2003;112:1652-5.

[3] Santanelli F, Mazzocchi M, Renzi L, Cigna E. Reconstruction of a natural-looking umbilicus. Scand J Plast Reconstr Surg Hand Surg. 2002;36:183-5.

[4] Morshed G. A Simple New Technique for Neo-Umbilicoplasty. Med. J. Cairo Univ., 2012, 80( 1): 759-761.

[5] Yotsuyanagi T, Nihei Y, Sawada Y. A simple technique for reconstruction of the umbilicus, using two twisted flaps. Plast Reconstr Surg J. 1998;102:2444.

[6] Abenavoli FM, Cusano V, Cucchiara V, et al. An idea for umbilicus reconstruction. Ann Plast Surg J.2001;46:194.

[7] Donnabella A. Anatomical reconstruction of the umbilicus. Rev. Bras. Cir. Plást. 2013, 28 (1 ): Jan./Mar. 119-123.

[8] Lee YT, Kwon C, Rhee SC, Cho SH, Eo SR. Four flaps technique for neoumbilicoplasty. Arch Plast Surg. 2015 May;42(3):351-5

[9] IIDA N. and OHSUMI N.: Reconstruction of umbilical hypogenesis accompanied by a longitudinal scar. Plast. Reconstr. Surg., 111: 322-5, 2003.

[10] Pfulg M, Van de Sijpe K, Blondeel P. A simple new technique for neo-umbilicoplasty. Br J Plast Surg.2005;58:688-691.

[11] Marconi F. Reconstruction of the umbilicus: A simple technique. Plast Reconstr Surg J. 1995;95:1115.

[12] Bartsich SA, Schwartz MH. Purse-string method for immediate umbilical reconstruction. Plast Reconstr Surg. 2003;112:1652-1655.

[13] Kirianoff TG. Making a new umbilicus when none exists. Plast Reconstr Surg J. 1978;61:603.

[14] Pardo Mateu L, Chamorro Hernandez JJ. Neoumbilicoplasty Through a Purse-String Suture of Three Defatted Flaps. Aesthetic Plast Surg. 1997 Sep-Oct;21(5):349-51.

[15] Bruekers SE1, van der Lei B, Tan TL, Luijendijk RW, Stevens HP. "Scarless" umbilicoplasty: a new umbilicoplasty technique and a review of the English language literature. Ann Plast Surg. 2009 Jul;63(1):15-20. 